\title{
Aplicação da biomassa Saccharomyces cerevisiae como agente adsorvente do corante Direct Orange 2GL e os possíveis mecanismos de interações adsorbato/adsorvente
}

\author{
Application of biomass Saccharomyces \\ cerevisiae as adsorption agent of dye \\ Direct Orange 2GL and possible \\ interactions mechanisms \\ adsorbate/adsorbent
}

Carolina Rosai Mendes ${ }^{1}$, Guilherme Dilarri ${ }^{1}$, Ronaldo Teixeira Pelegrini ${ }^{2}$

\footnotetext{
${ }^{1}$ Ciências Biológicas, Universidade Federal de São Carlos - Centro de Ciências Agrárias (UFSCar), Rodovia Anhanguera, km 174, Araras/SP. e-mail: carolina_rosai@hotmail.com

${ }^{2}$ Professor PhD. Universidade Federal de São Carlos - Centro de Ciências Agrárias (UFSCar), Araras/SP.
}

\section{RESUMO}

Os efluentes têxteis liberam grandes quantidades de resíduos de corantes no meio ambiente, poluindo e alterando todo o ecossistema aquático. Além da poluição visual os compostos possuem alta toxicidade, quando não tratado corretamente podem gerar bioacumulação na biota. A levedura Saccharomyces cerevisiae, comumente utilizada como biocatalizador nas indústrias, é um possível adsorvente, devido à estrutura química composta pela parede celular, contendo grupos amino sítio ativo de possíveis interações com os grupamentos sulfônicos pertencentes aos corantes reativos, cuja comercialização compreende em escala mundial. Para tanto, foi realizado um estudo de remoção do corante reativo Direct Orange 2GL pelo método de adsorção, utilizando analises em espectrofotômetro de UV-Vis, mediante a diferentes concentrações de biomassa de $S$. cerevisiae e valores de $\mathrm{pH}$ em solução. O experimento foi analisado a partir do gráfico de isotermas de adsorção, visando à capacidade máxima de adsorção do corante na parede celular da levedura a partir do tratamento matemático usando como modelo as equações de Langmuir e Freundlich e suas linearizações. Os experimentos ressaltaram os possíveis mecanismos de interações químicas, entre adsorbato/adsorvente, podendo apresentar formação em monocamadas ou multicamadas a partir do coeficiente de correlação relativo mediante a influência do valor de $\mathrm{pH}$. As analises em espectrofotômetro UV-Vis, exibiram eficiência no decréscimo dos valores de absorvância em relação ao valor no pico de onda máximo, com resultados de 0,063 absorvância, sendo este um valor aceitável para o padrão de absorvância permitido no descarte de corante. Desse modo, a utilização de biomassa de $S$. cerevisiae propicia resultados relevantes mesmo a baixas concentrações desde que ajustado os valores de $\mathrm{pH}$ em solução.

Palavras-chave: adsorção, corante têxtil, levedura.

\section{ABSTRACT}

The textile effluents release large amounts of dye waste in the environment, polluting and altering the whole aquatic ecosystem. Besides the visual pollution compounds have high toxicity, if not treated properly can generate bioaccumulation in biota. The yeast Saccharomyces cerevisiae, commonly used as a biocatalyst in industries is a possible adsorbent due to the chemical structure composed of the cell wall containing amino groups, active site location of possible interactions with sulfonic groups belonging to reactive dyes, which marketing worldwide. This way, it was performed to removal study of reactive dye Direct Orange 2GL by adsorption method using a spectrophotometer analysis of UV-Vis to the different biomass concentrations of $S$. 
cerevisiae and $\mathrm{pH}$ values in solution. The experiment was analyzed from the adsorption isotherms graphic, aiming at maximum capacity dye adsorption on the cell wall of the yeast by the mathematical treatment using as a model the equations of Langmuir and Freundlich and its linearization. The experiments pointed out the possible mechanisms of chemical interactions between the adsorbate/adsorbent may show forms of monolayers or multilayers by the correlation coefficient concerning on the influence of the $\mathrm{pH}$. The analysis in UVVis spectrophotometer, showed efficiency in the decrease in absorbance values relative to the value at of maximum wavelength, with results of the 0.063 absorbance, which is an acceptable value for the standard absorbance allowed the dye disposal. So, the use of biomass $S$. cerevisiae provides relevant results even at low concentrations since the $\mathrm{pH}$ adjusted solution.

Keywords: Adsorption, textile dye, yeast.

\section{INTRODUÇÃO}

Os problemas ambientais estão cada vez mais evidentes na sociedade contemporânea e são observados através das diversas alterações físicas, químicas e biológicas no âmbito qualidade do solo, ar e água. Um dos grandes problemas do século está ligado à qualidade do corpo hídrico que ultrapassa em muitos trechos os padrões estabelecidos como toleráveis.

As atividades industriais têxteis consomem muita água em seus processos, gerando elevado volume de efluentes e consequentemente, contribuindo para o aumento dos níveis de contaminantes em águas naturais [1].

Estima-se que 10-15\% total da carga orgânica de corantes entram no meio ambiente através dos efluentes industriais [2]. A carga orgânica liberada altera o ecossistema, devido ao aumento de turbidez na água, dificulta a penetração da radiação solar o que gera modificações na atividade fotossintética e o regime de solubilidade dos gases [3]. Ademais, os corantes possuem compostos tóxicos em sua molécula, tais como, benzeno, tolueno e etil-benzeno, naftaleno, antraceno e xileno [4]. Esses compostos causam perigo de bioacumulação e riscos de eco-toxicidade, podendo permanecer por 50 anos no meio ambiente $[5,6,7]$.

Dentre as classes de corantes têxteis disponíveis atualmente, encontram-se os ácidos, básicos, dispersos, azoicos, diazóicos, metalizados e os reativos que são amplamente utilizados nas indústrias e já representam $60 \%$ do consumo mundial [8].

Em geral, a cor de um corante é o resultado da interação dos grupos funcionais cromóforos entre funções azo (-N=N-) e espécies aromáticas [9].

Os grupos funcionais, denominados auxocromos, em corantes reativos podem ser cloro, hidroxila, bromo, nitro, sulfônico, amino, metóxi, etóxi e etila [10], que permitem alcançar diferentes tonalidades de cores através de efeitos hipsocrômicos e batocrômicos.

Devido aos problemas decorrentes ambientais, muitos estudos associados a novas tecnologias têm sido propostos para o tratamento de efluentes têxteis, como por exemplo, a ozonização [11], fluxo subcrítico [12], degradação biológica [13], adsorção [14] e biossorção [15].

Recentemente, muitas pesquisas apontam para o uso de microrganismos em processos de descoloração de corante têxtil utilizando método de adsorção [16].

A adsorção utilizando biomassa microbiana pode ser definida como uma ligação do soluto ao organismo, através de um processo que não envolve transporte de energia metabólica [17]. Além de proporcionar reconhecidas vantagens conforme descrito na literatura [18] a biomassa pode ser reutilizada; os compostos podem ser removidos da solução independentemente do grau de toxidez; os tempos de operação são pequenos quando o equilíbrio é alcançado; não produz compostos secundários com toxicidade elevada e pode ser altamente seletiva; o material adsorvido pode ser reutilizado; além de ser economicamente viável. Porém, a capacidade de adsorção depende do tipo de biomassa, o tipo de adsorbato, a presença de íons competidores no meio e valor de $\mathrm{pH}$ [19].

Entre os diversos tipos de biomassa pesquisada, os fungos tem apontado ser particularmente apropriados para o processo de tratamento de efluente têxtil por adsorção [20, 21, 22], devido à capacidade de retenção seletiva através da formação de sítios ativos associados à parede celular do microrganismo [23].

A levedura Saccharomyces cerevisiae é um microrganismo aeróbio facultativo, isto é, que tem a habilidade de se ajustar metabolicamente, tanto em condições de aerobiose como de anaerobiose [24]. Do ponto de vista industrial, S. cerevisiae é um dos biocatalizadores mais comuns, devido principalmente a sua fácil disponibilidade, baixo custo, não requerimento de instrumentos especiais, fácil manipulação, não patogenicidade [25]. 
Para tanto, esse estudo visa avaliar o potencial de adsorção do corante Direct Orange 2GL de caráter comercial reativo contendo grupamento sulfônico, por biomassa de Saccharomyces cerevisiae. Afim, de minimizar os impactos ambientais hídricos, causados por resíduos de efluentes têxteis. Ademais, são propostos os possíveis mecanismos de interações químicas entre a biomassa e o corante, a partir do tratamento matemático respeitando as equações de Langmuir e Freundlich.

\section{MATERIAIS E MÉTODOS}

\subsection{Corante}

O corante Direct Orange 2GL (Figura 1), pertencente ao grupo dos reativos sulfonantes, possui número de registro no banco de dados do Chemical Abstract Service (CAS) 1325-54-8, peso molecular de 299 g.mol ${ }^{-1}$ e fórmula empírica $\mathrm{C}_{12} \mathrm{H}_{10} \mathrm{~N}_{3} \mathrm{NaO}_{3} \mathrm{~S}$. Foi submetido ao estudo sem purificação prévia.

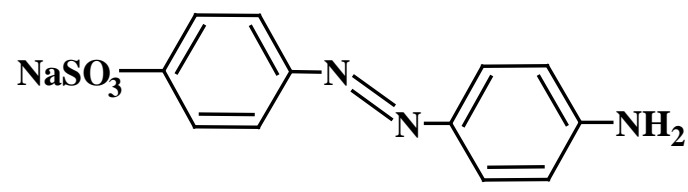

Figura 1: Fórmula estrutural do corante reativo Direct Orange 2GL.

\subsection{Saccharomyces cerevisiae}

A levedura Saccharomyces cerevisiae foi utilizada nesse estudo a partir do fermento biológico comercializado, em forma liofilizada, pela Pak Gida Uretim ve Pazarlama A. S. Cd. No: 5/6 34349, Lote: 36936614. Foram feitas pesagens de 500; 800; 1000 mg para os ensaios de adsorção em estudo de bancada.

\subsection{Estudo do corante em relação à variação de valor de pH}

No estudo de variação no valor de $\mathrm{pH}$ as soluções do corante Direct Orange 2GL foram avaliados a partir da concentração de $100 \mathrm{mg} / \mathrm{L}$, de modo a medir as variações no comprimento de onda do corante.

Os valores de $\mathrm{pH}$ foram alterados através da adição, utilizando soluções de ácido clorídrico 0,1 mol/L ( $\mathrm{HCl}$ ) e hidróxido de sódio $0,1 \mathrm{~mol} / \mathrm{L}(\mathrm{NaOH})$. O equipamento pHmetro de bancada (Tecnopon, modelo MPA-210) foi empregado para monitorar os valores de $\mathrm{pH}=2,8 ; \mathrm{pH}=5,2 ; \mathrm{pH}=6,6 \mathrm{e} \mathrm{pH}=9,3$.

No estudo foi verificado o efeito dos valores de $\mathrm{pH}$ nas alterações de cor por efeitos de deslocamento batocrômico (deslocamento da banda de absorção no comprimento de onda maior, dentro do espectro visível) ou hipsocrômicos (deslocamento da banda de absorção no comprimento de onda menor, dentro do espectro visível). Desse modo, as análises nos diferentes valores de $\mathrm{pH}$ foram feitas utilizando cubetas de quartzo e um espectrofotômetro de Ultravioleta-Visível (Thermo Scientific, modelo BioMate 3S), com varredura entre 300 a $800 \mathrm{~nm}$.

\subsection{Curva de calibração do corante Direct Orange 2GL}

A fim, de quantificar a concentração do corante remanescente em solução nos estudos de adsorção, preparouse uma solução padrão inicial de $100 \mathrm{mg} / \mathrm{L}$, a partir desta, foram realizadas diluições secundárias cujas concentrações finais seguiram em 0,5 mg/L, 1 mg/L, 2 mg/L, 5 mg/L, 10 mg/L, 20 mg/L, 30 mg/L, 40 mg/L.

Foram realizadas varreduras nos comprimentos de onda de 300 a $800 \mathrm{~nm}$ em espectrofotômetro UVVis para cada concentração do corante, utilizando nas análises cubeta de quartzo com caminho óptico de 5 $\mathrm{mm}$.

A curva de calibração foi obtida através de diferentes concentrações do corante em função da absorbância a comprimento de onda máximo em análises no espectrofotômetro UV-Vis. A partir dos valores de absorbância no pico de onda máxima, foi possível obter um gráfico da reta padrão no programa Origin 6.0 para os valores de A, B e R na equação da reta (Equação 1).

$$
Y=A+B \cdot X
$$




\subsection{Isotermas de adsorção do corante Direct Orange 2GL}

Os ensaios de adsorção da solução do corante Direct Orange 2GL ocorreram mediante as diferentes concentrações de biomassa liofilizada de S. cerevisiae. As análises seguiram em função do tempo de contato de 120 minutos em estudo de bancada a temperatura ambiente de $25^{\circ} \mathrm{C}\left({ }^{+/-} 2^{\circ} \mathrm{C}\right)$.

O estudo foi realizado a partir da solução mãe do corante à concentração molar de $16,72 \times 10^{-2} \mathrm{mmol} / \mathrm{L}$ (50 mg/L) a diferentes potenciais hidrogeniônicos, nos valores de $\mathrm{pH}=4 ; \mathrm{pH}=5 ; \mathrm{pH}=6$.

Foram adicionadas simultaneamente variações de biomassa como agente adsorvente a 500 mg; 800 mg; 1000 mg em Beakers contendo $30 \mathrm{~mL}$ da solução do corante e nulo considerando o controle.

Para cada amostra foram retiradas alíquotas, após o período de equilíbrio e posteriormente centrifugada (centrífuga marca CentriBio) a uma rotação de 4.000 rpm por 15 minutos e analisadas em espectro UVVis entre 300 a $800 \mathrm{~nm}$.

O experimento foi analisado a partir do gráfico de isotermas, utilizando os modelos da equação de Langmuir (Equação 2) e a sua linearização (Equação 3), Freundlich (Equação 4) e a sua linearização (Equação 5), afim de calcular a capacidade máxima $\left(\mathrm{q}_{\mathrm{m}}\right)$ de adsorção da parede celular de $S$. cerevisiae nos valores de $\mathrm{pH}=4, \mathrm{pH}=5$ e $\mathrm{pH}=6$.

$$
\begin{aligned}
& q=\frac{K q m \cdot C e}{1+K C e} \\
& \frac{C e}{q}=\frac{C e}{q m}+\frac{1}{K q m} \\
& n \cdot \log C e=\log \left(\frac{x}{m}\right)-\log K \\
& \log \left(\frac{x}{m}\right)=\log K+n \cdot \log C e
\end{aligned}
$$

Sendo, (q) a concentração do corante; (qm) a capacidade máxima de adsorção; (K) a constante de equilíbrio relacionada com a energia livre de adsorção que corresponde à afinidade entre a superfície da parede celular da levedura e o soluto e (Ce) a concentração de equilíbrio; (n) a inclinação, (Log K) o intercepto em $(\mathrm{Y})$.

\subsection{Cinética de adsorção do corante Direct Orange 2GL}

Para tanto, foi preparado uma solução inicial de concentração 50 mg/L do corante e distribuído em três Beakers com volumes iguais de $30 \mathrm{~mL}$. Em cada, foram adicionados $500 \mathrm{mg} ; 800 \mathrm{mg}$ e $1000 \mathrm{mg}$ de biomassa liofilizada de $S$. cerevisiae no valor de $\mathrm{pH}=6$.

As determinações do corante em solução foram realizadas em intervalos sequenciais de 15 minutos, durante 105 minutos.

As análises foram avaliadas por espectrofotometria UV-Vis com valores de absorbância ajustados segundo a curva de calibração por quantificação do corante em mg/L.

\section{RESULTADOS E DISCUSSÃO}

No estudo de variação do valor de $\mathrm{pH}$ a solução do corante reativo Direct Orange 2GL, não apresentou variações de absorbância e/ou deslocamento no comprimento de onda, característicos de efeitos batocrômico ou hipsocrômicos. Dessa forma, foi possível a quantificação do corante para a curva de calibração, sem a utilização de uma solução tampão para ajustar o valor de $\mathrm{pH}$.

O comprimento de onda máxima da solução do corante se estabeleceu em $413 \lambda$. Ademais, o corante apresentou valor de pH 6,2 em solução.

As concentrações de corante remanescente nas soluções foram realizadas a partir da curva de calibração. A partir da curva os parâmetros como linearização, coeficiente angular, coeficiente linear foram avaliados segundo a equação da reta através de um software Origin 6.0. 
A equação da reta $\mathrm{Y}=\mathrm{A}+\mathrm{B} . \mathrm{X}$, onde o coeficiente linear $\mathrm{A}=0,0038$; coeficiente angular $\mathrm{B}=$ 0,03361; Y foram às leituras de absorbância para os estudos de isoterma e cinética; e para X os valores de concentração.

Com relação ao coeficiente de correlação linear o valor foi $\mathrm{R}=0,99998$, o que indica excelente ajuste linear em relação aos pontos da curva de calibração.

Os estudos de bancada apresentaram isotermas de adsorção com resultado mais eficiente em valor de $\mathrm{pH}=4$ do que em valores de $\mathrm{pH}=5$ e $\mathrm{pH}=6$ (Figura 2). Isso ocorre em função às características da parede celular da levedura $S$. cerevisiae e do corante com relação aos seus grupos funcionais descrito na literatura [19].

Em valor de $\mathrm{pH}=4$, os grupos funcionais da parede celular possuem mais quantidades de sítios ativos disponíveis $\left(-\mathrm{NH}_{3}{ }^{+}\right)$, devido ao grau de acidificação, do que nos valores de $\mathrm{pH}=5$ e $\mathrm{pH}=6$. Desse modo quando comparados, o valor de $\mathrm{pH}=4$ obteve melhor desempenho, entretanto os valores de $\mathrm{pH}=5$ e $\mathrm{pH}=6$, também obtiveram resultados de remoção do corante em solução.

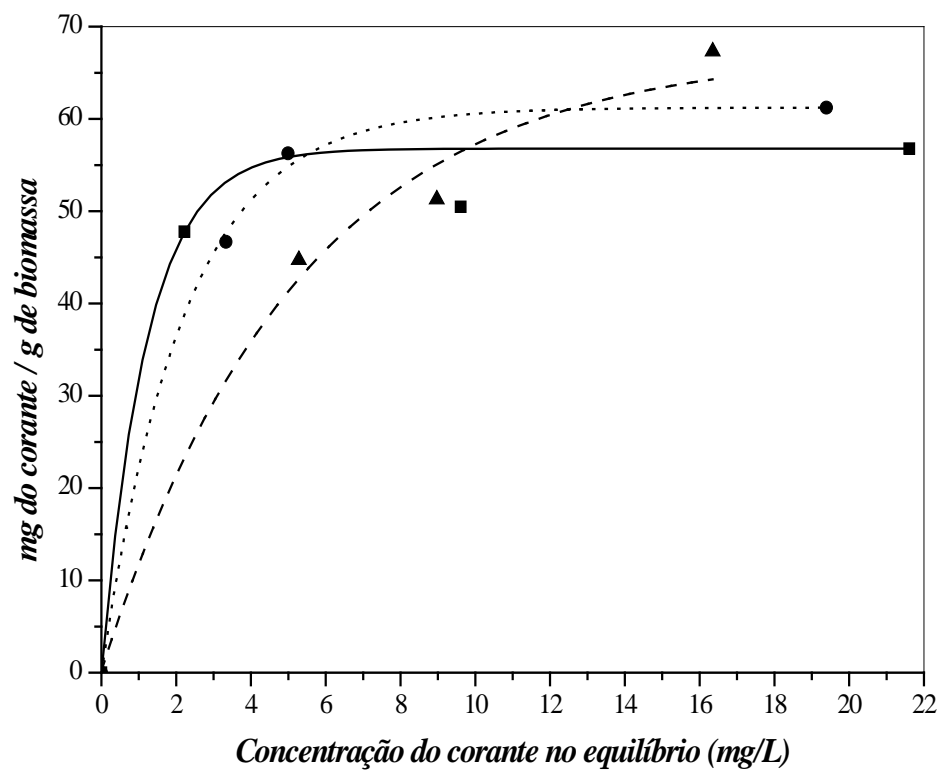

Figura 2: Isotermas do corante Direct Orange 2GL nos diferentes valores de $\mathrm{pH}=4$ , $\mathrm{pH}=5$ ), $\mathrm{pH}=6(\Delta), \mathrm{du}-$ rante o estudo de bancada.

A linearização das isotermas de Langmuir e Freundlich possibilitou determinar a capacidade máxima (qm) dos estudos de adsorção com variações nos valores de pH. Além de possibilitar a determinação do efeito de interação adsorbato/adsorvente, analisando a adsorção através de monocamadas ou multicamadas. Cada valor de $\mathrm{pH}$ apresentou um padrão de coeficiente de correlação relativo (R) para cada isoterma, como mostrado na Tabela 1.

Tabela 1: Coeficiente de correlação relativo (R) para analises de isotermas.

\begin{tabular}{l|l|l}
\hline VALOR DE PH & FREUNDLICH & LANGMUIR \\
\hline $\mathrm{pH}=4$ & 0,95206 & 0,99793 \\
\hline $\mathrm{pH}=5$ & 0,83100 & 0,99976 \\
\hline $\mathrm{pH}=6$ & 0,98045 & 0,97073 \\
\hline
\end{tabular}

Estudos sobre a composição da parede celular de $S$. cerevisiae revelaram a presença de glucana (48 $60 \%$ ), que é um polímero de unidades de glicose com ligações $\beta(1-3)$ e $\beta(1-6)$, manoproteínas (20 - 23\%), quitina (0,6 - 2,7\%), que é composta por $\beta(1-4) \mathrm{N}$-acetilglicosamina e uma pequena porção de lipídios [26]. A distribuição destes componentes está organizada em duas camadas principais, sendo a externa composta de 
manoproteínas e, a interna de glucana e quitina, em uma estrutura interconectada por ligações covalentes [27].

De maneira geral, a parede celular da levedura S. cerevisiae é considerada o local de prevalência de sítios de ligação de corantes, tais como os grupos químicos acetamido, amido, fosfato, amino, amina, sulfidrila, carboxila e hidroxila [28].

O corante Direct Orange 2GL, possui características intrínsecas de grupos reativos sulfônicos, o que confere solubilidade em meio aquoso. Em solução o íon sódio $\left(\mathrm{Na}^{+}\right)$dissocia-se e propicia o aparecimento do grupo sulfônico $\left(-\mathrm{SO}_{3}{ }^{-}\right)$, capaz de formar ligações de caráter iônicas, como por exemplo, aos grupos amino. Desse modo, argumentam-se possíveis mecanismos de interações entre o corante e a quitina encontrada na parede celular da levedura $S$. cerevisiae, respeitando as isotermas de Langmuir e Freundlich.

Conforme apresentado nas isotermas a valores de $\mathrm{pH}=4$ e $\mathrm{pH}=5$ os resultados demostraram adsorção por monocamadas, respeitando a equação da isoterma de Langmuir. Desse modo, em meio acidificado, é proposto que a parede celular da levedura acresça as quantidades de sítios ativos disponíveis para ligação do corante, devido aos grupamentos amino protonados $\left(-\mathrm{NH}_{3}{ }^{+}\right)$que propiciam o surgimento de fortes interações com o sítio básico dos grupos sulfônicos $\left(-\mathrm{SO}_{3}{ }^{-}\right)$do corante (Figura 3).

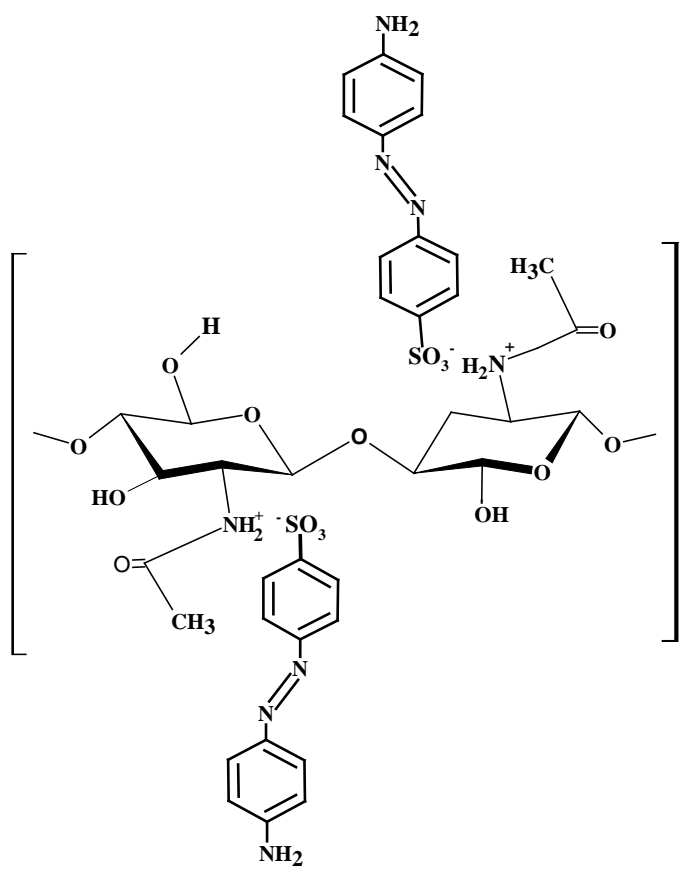

Figura 3: Possível ligação de hidrogênio entre o grupo amino da quitina presente na parede celular de Saccharomyces cerevisiae e o grupo sulfônico da molécula do corante.

Outro mecanismo proposto, também respeita a equação da isoterma de Langmuir, sendo monocamada e podem ocorrer por meio de ligações de hidrogênio entre os grupamentos sulfônicos $\left(-\mathrm{SO}_{3}{ }^{-}\right)$e os grupos hidroxi $\left(-\mathrm{OH}_{2}^{+}\right)$presentes na quitina da parede celular da levedura (Figura 4). 


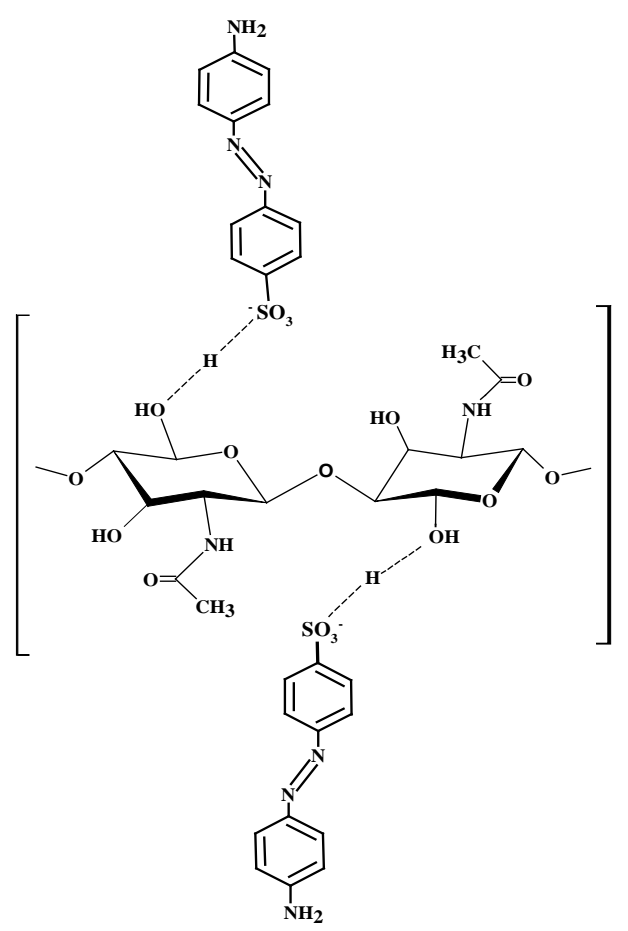

Figura 4: Possível ligação de hidrogênio do grupo hidroxi da quitina presente na parede celular de Saccharomyces cerevisiae e o grupo sulfônico da molécula do corante.

Em valor de $\mathrm{pH}=6$ os grupos amino $\left(-\mathrm{NH}_{2}^{+}\right)$da quitina se encontram em menor numero protonados, podendo ocorrer ligação do corante com a parede celular da levedura através de ligação de hidrogênio. Portanto, a adsorção respeita à equação da isoterma de Freundlich, sendo uma adsorção em múltiplas camadas de interações reunidas á volta da parede celular do micro-organismo. Isso pode ocorrer devido às ligações de hidrogênio entre o corante e a quitina, além das interações das moléculas de corante em outras moléculas de corante, através da ligação de hidrogênio do grupamento azo $(-\mathrm{N}=\mathrm{N}-)$ com o grupo amino $\left(-\mathrm{NH}_{2}\right)$ mostrado na figura 5. Esse tipo de ligação é mais fraco, quando comparada com as ligações covalentes que ocorrem em valores de $\mathrm{pH}=4$ e $\mathrm{pH}=5$.

Desta forma, a adsorção do corante pela levedura a valor de $\mathrm{pH}=6$ torna-se inferior aos valores de $\mathrm{pH}=4$ e $\mathrm{pH}=5$.

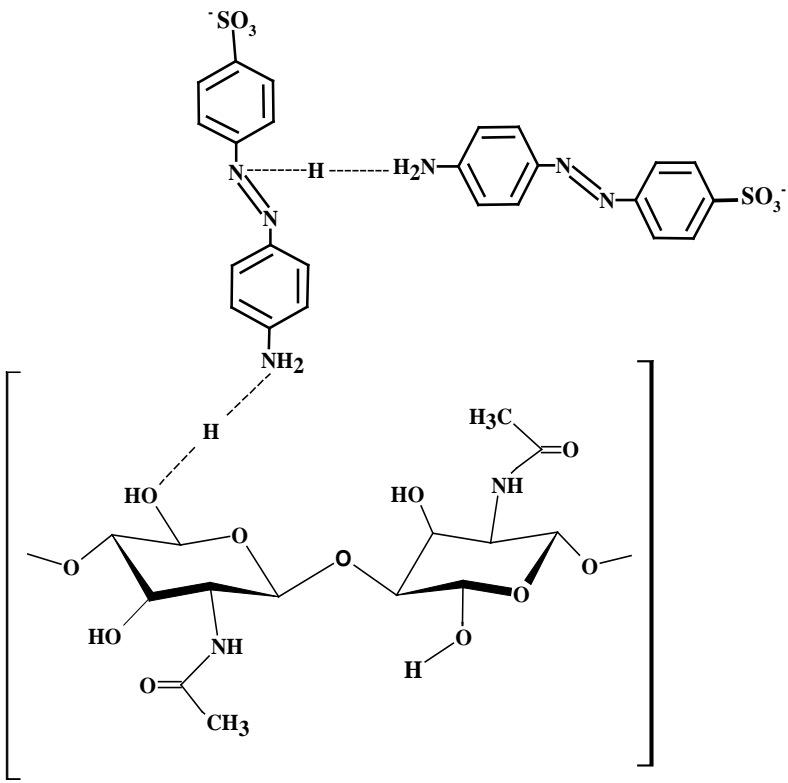

Figura 5: Possível ligação iônica entre o grupo azo (-N=N-) na molécula do corante e o grupo sulfônico (-SO $\left.{ }_{3}^{-}\right)$da molécula do corante. 
No estudo cinético foi observado o tempo mínimo necessário para o sistema biomassa/corante atingir as condições de equilíbrio. A figura 6 apresenta a evolução cinética da remoção do corante em função do tempo. Para os valores de $1000 \mathrm{mg}$ e $800 \mathrm{mg}$ de biomassa de $S$. cerevisiae, o sistema entra em equilíbrio a partir de 60 minutos; para 500 mg de biomassa o sistema entra em equilíbrio a partir de 90 minutos.

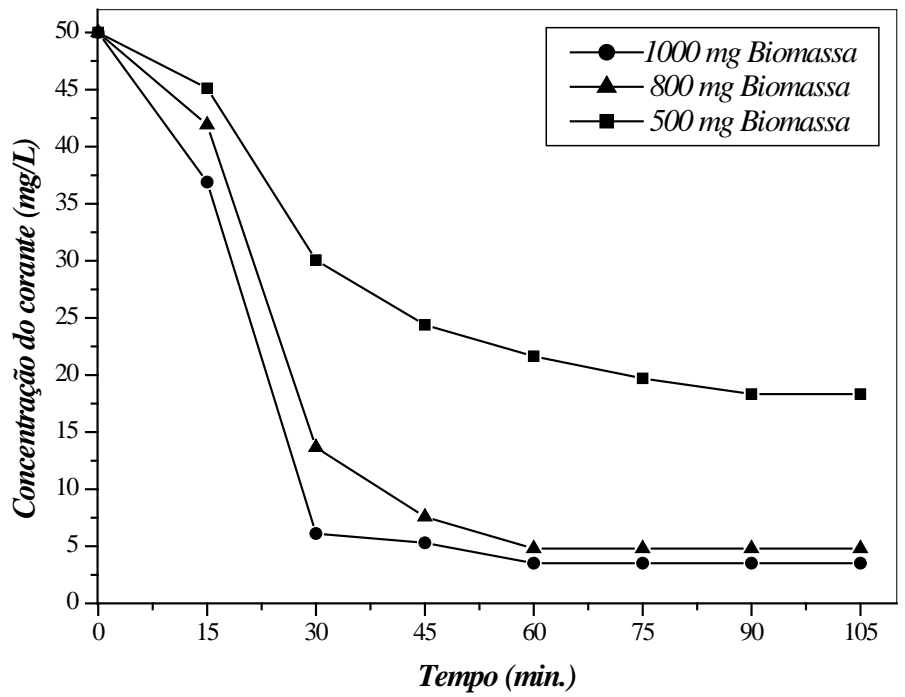

Figura 6: Cinética de adsorção do corante reativo Direct Orange 2GL.

A efetividade da remoção da cor em solução pode ser avaliada por um padrão espectrofotométricamente permitido, definido na literatura [29]. De modo geral, é possível avaliar o grau de contaminação através da absorbância do resíduo em solução, sendo tolerável até 0,06 Absorbância.

O estudo demonstrou a partir de análises em espectrofotômetro UV-Vis o decréscimo nos valores de absorbância em relação ao valor no pico de onda máximo de 1,6 de absorbância (controle) para valores de 0,063 de absorbância, utilizando 1000 mg de biomassa de S. cerevisiae em valor de pH=4 (Figura 7). Desse modo foi possível produzir um histograma em função da absorbância de cada valor de biomassa, levando em relação o padrão espectrofotômetro permitido (Figura 8). Contudo, o uso de biomassa é diretamente proporcional à redução da coloração, o que permite alcançar resultados ainda menores quando comparados ao valor de absorvância permitido.

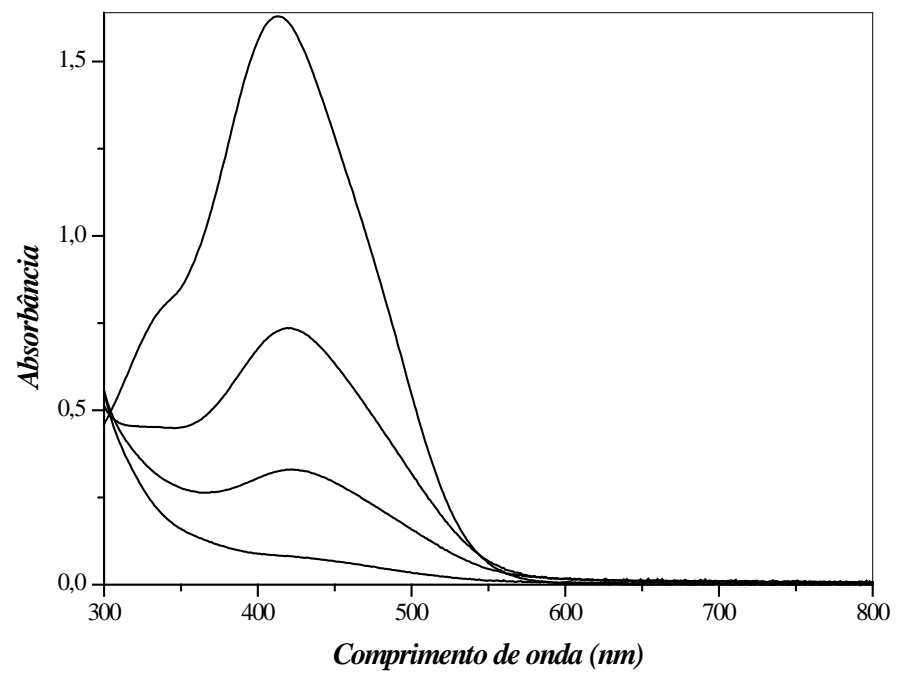

Figura 7: Espectro UV-Vis da redução no valor de absorbância em 60 minutos a partir da adsorção em valor de pH=4. 


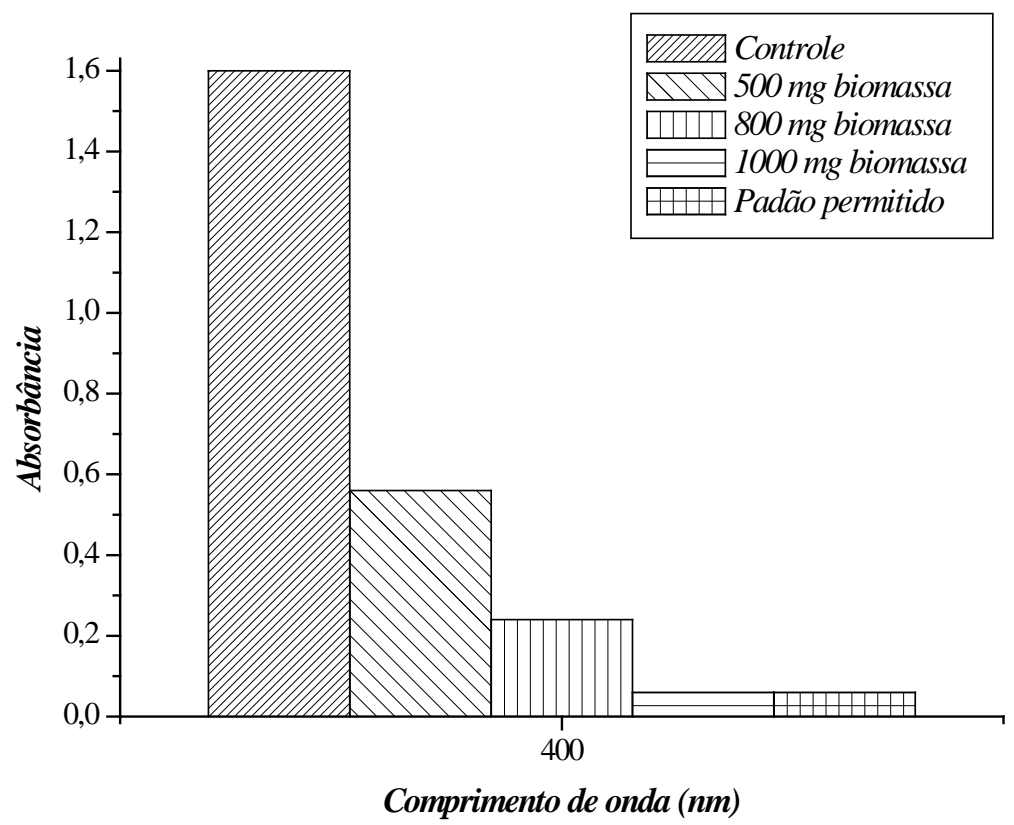

Figura 8: Histograma da adsorção do corante Direct Orange 2GL por análise espectrofotométrica em comparação ao padrão permitido.

\section{CONCLUSÕES}

Os estudos evidenciam o possível potencial da biomassa de Saccharomyces cerevisiae para o tratamento de águas residuárias de indústrias têxteis contaminadas com o corante reativo Direct Orange 2GL.

A biomassa de levedura além de mostrar eficiência no tempo de tratamento do corante, também se destaca pela facilidade de decantação da biomassa, desse modo, o efluente tratado é descartado sem o microorganismo. Ademais, a levedura não é patogênica e o custo benefício é baixo devido sua ampla utilização em diversos setores industriais.

As analises em espectrofotômetro UV-Vis, exibiram eficiência na remoção do corante em solução com resultados de 0,063 Absorbância. Foi possível observar uma diferença significativa em relação à adsorção quando o valor de $\mathrm{pH}$ variou. Isso se deve ao número de sítios ativos formados, diretamente proporcionais à acidificação da solução. Ademais, os resultados são aceitáveis aos padrões permitidos quando ajustados os valores de pH em solução. Para tanto, foi possível propor alguns mecanismos de interações entre adsorbato/adsorvente por meio do coeficiente de correlação relativo respeitando as equações de Langmuir e Freundlich, sendo monocamada ou multicamadas a nível molecular.

\section{AGRADECIMENTOS}

Centro de Ciências Agrárias - Universidade Federal de São Carlos (UFSCar).

\section{BIBLIOGRAFIA}

[1] SALLES, P. T. F., PELEGRINI, N. N. B., PELEGRINI, R. T. "Tratamento eletroquímico de efluente industrial contendo corantes reativos”, Engenharia Ambiental, v.3, n.2, pp.25-40, 2006.

[2] REVANKAR, M.S., LELE, S.S. "Synthetic dye decolorization by Ganoderma sp. WR-1", Bioresourse Technology, v.98, pp.775-780, 2007.

[3] SOUZA, J.B., DANIEL, L.A. “Comparação entre Hipoclorito de Sódio e Ácido Peracético na Inativação de E. Coli, Colifagos E C. perfringens em Água com Elevada Concentração de Matéria Orgânica”, Engenharia Sanitária e Ambiental, v. 10, p. 111-117, 2005.

[4] GONG, R., ZHANG, X., LIU, H., et al., "Uptake of cationic dyes from aqueous solu tion by biosorption onto granular kohlrabi peel”, Bioresource Technology, v.98, pp.1319-1323, 2007. 
[5] CONTRERAS, L., SEPULVEDA, L., PALMA, C. "Valorization of Agro-industrial Wastes as Biosorbent for the Removal of Textile Dyes from Aqueous Solutions”, International Journal of Chemical Engineering, v.679352, pp.9-13, 2012.

[6] HASSAN, A. F., ABDELMOHSEN, A. M., FOUDA, M. M. G. "Comparative study of calcium alginate, activated carbon, and their composite beads on methylene blue adsorption", Carbohydrate Polymers, v.102, pp.192-198, 2014.

[7] ZHU, M., MENG, D., WANG, C., et al. "Degradation of methylene blue with H2O2 over a cupricoxide nanosheet catalyst”, Chinese Journal of Catalysis, v.34, pp.2125-2129, 2013.

[8] CATANHO, M., MALPASS, G. R. P., MOTHEO, A. J. “Avaliação dos Tratamentos Eletroquímico e Fotoeletroquímico na Degradação de Corantes Têxteis”, Química Nova, v.29, pp.983-989, 2006.

[9] GALINDO, C., KALT, A. "UV/H2O2 oxidation of azodyes in aqueous media: evidence of a structure degradability relationship”, Dyes and Pigments, v.42, pp.199-207, 1999.

[10] KIMURA, I. Y., FÁVERE, V. T., LARANJEIRA, M. C. M., et al., "Avaliação da capacidade de adsorção do corante reativo laranja 16 pela quitosana”, Acta Scientiarum, v.22, n.5, pp.1161-1166, 2000.

[11] SANTOS, P. K., FERNANDES, K. C.,FARIA, L. A., et al., "Descoloração e degradação do azo corante vermelho GRLX-220 por ozonização”, Química Nova, v.34, n.8, pp.1315-1322, 2011.

[12] HOSSEINI, S. D., ASGHARI, F. S., YOSHIDA, H. "Decomposition and discoloration of synthetic dyes using hot/liquid (subcritical) water”, Water Research, v.44, pp.1900-1908, 2010.

[13] KAMIDA, H. M., DURRANT, L. R. "Biodegradação de efluente têxtil por Pleurotus sajor-caju.” Química Nova, v.28, n.4, pp.629-632, 2005.

[14] EL-KHAIARY, M. I., GAD, F. A., MAHMOUD, M. S., et al., "Adsorption of methylene blue from aqueous solution by chemically treated water hyacinth”, Toxicological and Environmental Chemistry, v.91, n.6, pp.1079-1094, 2009.

[15] MÓDENES, A. N., ESPINOZA, F. R., ALFLEN, V. L., et al., "Utilização da macrófita Egeria densa na biossorção do corante reativo 5G”, Engevista, v.13, pp.3-15, 2011.

[16] OGUGBUE, C. J., SAWIDIS, T. "Bioremediation and detoxification of synthetic wastewater containing triarylmathane dyes by Aromonas hydrophila isolated from industrial effluents", Biotechnology research international, v. 2011, pp.1-11, 2011.

[17] KAUSHIK, P., MALIK, A. "Fungal dye decolourization: Recent advances and future potential”, Environment International, v.35, pp.127-141, 2009.

[18] FÁVERE, V. T., RIELLA, H. G., ROSA, S. “Cloreto de N-(2-hidroxil) propil-3-trimetil amônio quitosana como adsorvente de corantes reativos em solução aquosa”, Química Nova, v.33, pp.14761481, 2010.

[19] MITTER, E. K., SANTOS, G. C., ALMEIDA,E. J. R., et al. "Analysis of acid Alizarin Violet N Dye Removal Using Sugarcane bagasse aas adsorbent”, Water, Air and Soil Pollution, v.223, n.2, pp.765-770, 2012.

[20] PRIGIONE, V., TIGINI, V., PEZZELLA, C., et al., "Decolourisation and detoxi fication of textile effluents by fungal biosorption”, Water Research, v.42, pp.2911-2920, 2008.

[21] AKSU, Z., TEZER, S. "Equilibrium and kinetic modeling of biosorption of Remazol Black B by Rhizopus arrhizus in a batch system: effect of temperature”, Process Biochemistry, v.36, pp.431-439, 2000.

[22] YESILADA, O., ASMA, D., CING, S., "Decolorization of textile dyes by fungal pellets”, Process Biochemistry, v.38, pp.933-938, 2003.

[23] SUMATHI, S., MANJU, B. S. "Uptake of reactive textile dyes by Aspergillus foetidus”, Enzyme Microbiology Technology, v.27, pp.347-355, 2000.

[24] DOS SANTOS, J. R. A., GUSMÃO, N. B., GOUVEIA, E. R. "Seleção de linhagem industrial de Saccharomyces cerevisiae com potencial desempenho para produção de etanol em condições adversas de temperatura e de agitação”, Revista Brasileira de Produtos Agroindustriais, v.12, n.1, pp.75-80, 2010.

[25] BARALDI, P. T., CORRÊA, A. G. “O emprego de fermento de pão, Saccharomyces cerevisiae, na síntese de feromônio”, Química Nova, v.27, n.3, pp.421-431, 2004.

[26] FLEET, G. H. "Composition and structure of yeast cell walls”, Current Topics in Medical Mycology, v.1, n.1, pp.24-24, 1985. 
[27] HA, C. H., LIM, K. H., KIM, Y. T., et al., "Analysis of alkali- soluble glucan produced by Saccharomyces cerevisiae wild-type and mutants”, Applied Microbiology and Biotechnology, v.58, n.3, pp.370-377, 2002.

[28] VOLESKY, B., HOLAN, Z. R. "Biosorption of Heavy Metals”, Biotechnology, v.11, pp.235-250, 1995. [29] COOPER, P. "Removing colour from dyehouse waste waters - a critical review of technology available”, Journal of the Societyof Dyes and Colourists, v.109, n.3, pp.97-100, 1993. 